\title{
Slowing down: age-related neurobiological predictors of processing speed
}

\begin{abstract}
Mark A. Eckert*
Hearing Research Program, Department of Otolaryngology - Head and Neck Surgery, Medical University of South Carolina, Charleston, SC, USA
\end{abstract}

Processing speed, or the rate at which tasks can be performed, is a robust predictor of agerelated cognitive decline and an indicator of independence among older adults. This review examines evidence for neurobiological predictors of age-related changes in processing speed, which is guided in part by our source based morphometry findings that unique patterns of frontal and cerebellar gray matter predict age-related variation in processing speed. These results, together with the extant literature on morphological predictors of age-related changes in processing speed, suggest that specific neural systems undergo declines and as a result slow processing speed. Future studies of processing speed - dependent neural systems will be important for identifying the etiologies for processing speed change and the development of interventions that mitigate gradual age-related declines in cognitive functioning and enhance healthy cognitive aging.

Keywords: aging, processing speed, cerebellum, prefrontal, source based morphometry

Edited by:

Anna C. Nobre, University of Oxford, UK

Reviewed by:

Robert T. Knight, University of California Berkeley, USA

${ }^{*}$ Correspondence:

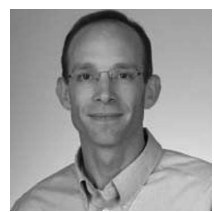

Mark A. Eckert is an Associate Professor of Otolaryngology - Head and Neck Surgery at the Medical University of South Carolina (MUSC). He trained at the University of Florida where his doctoral work was on the neurobiology of reading disability. His research focus has expanded to individual differences in neurobiology that underlie oral and written language abilities, and in collaboration with members of the MUSC Hearing Research Program, his work includes the study of aging neural systems that affect speech recognition. eckert@musc.edu
The white-knuckle experience of being a passenger in a car driven by an older adult with slow processing speed is a salient example of the significant impact that age-related slowing of motor function and decision making has on daily life. Age-related change in processing speed is a primary predictor of the cognitive declines that older adults experience (Salthouse and Ferrer-Caja, 2003) and is a strong predictor of people who need help with daily activities (Wahl et al., 2010). Understanding the neurobiological changes that contribute to age-related changes in processing speed is critical for developing interventions that limit age-related cognitive declines; a need that is underscored by the anticipated doubling in population by 2050 of adults over 60 years in developed countries (United Nations, Department of Economic and Social Affairs, Population Division, 2007).

Our interest in processing speed at the MUSC Hearing Research Program includes the impact of processing speed on auditory function declines that older adults experience. Slowed processing speed predicts auditory sensitivity to temporal changes in sounds (Harris et al., 2010), as well as lip reading (Feld and Sommers, 2009); a skill that benefits listeners in noisy conditions (MacLeod and Summerfield, 1987). These findings suggest that declines in processing speed influence information processing from low level sensory to higher cortical functions that are important for speech understanding. In short, declines in systems that support processing speed could significantly impact the ability of older adults to follow conversation, the efficacy of interventions for age-related hearing loss, and the efficacy of interventions in general.

Processing speed is typically assessed with timed tests of speeded behavior that involve multiple perceptual and cognitive functions, including stimulus perception, working memory, decision making and motor planning, motor performance, and sometimes adjusting motor performance after evaluating performance. Given that so many neural systems are required to perform a processing 


\section{Processing speed}

A behavioral construct that reflects the rate at which tasks can be performed. Processing speed is typically assessed with timed tasks in which the person must perform a task as quickly as possible. Historically, reaction time experiments could be considered as the earliest measures of processing speed.

\section{Age-related changes}

Neurobehavioral changes that occur with age are best characterized by longitudinal studies. In this review, change is used to describe results in the context of cross-sectional findings. It is likely that neural aging compounds or exaggerates the impact of individual variation in cognitive functions.

Source based morphometry A structural imaging analysis that involves comparing groups or correlating a particular measure with an estimate of volume from across a spatial pattern of voxels that have a common pattern of covariance. This technique reduces the number of comparisons that are typically performed in voxel-based morphometry analyses, while allowing one to identify unique effects and control for noise that may be reflected in a given pattern of covariance. This approach may be particularly valuable when a global latent variable like age influences voxel-based measures across the brain. speed task, it is not surprising that so much of our behavioral performance can be related to measures of processing speed. One processing speed test used in our research is a variant of the Trail Making Test called the Connections Test (Salthouse et al., 2000). The Connections Test was designed to limit motor demands and disambiguate perceptual and motor speed from working memory and inhibitory function. The Connections test involves the sequential search, target identification (numbers or letters), motor planning and response, performance monitoring, and identification of the next item in the sequence (alphabetic or numerical order). These functions can be dissociated from response inhibition and working memory by contrasting performance (Connections Simple) with a test in which subjects alternate between attending to numbers and letters (Connections Complex), thereby requiring a subject to keep the order in mind across stimulus dimensions and to inhibit inappropriate responses to the same stimulus dimension across two trials. The important point is that processing speed tests involve multiple functions requiring the coordination of multiple neural systems that are at risk for age-related declines.

The engagement of multiple neural systems for performing speeded tasks means that age-related decline across a variety of neural systems could have additive effects on processing speed. This also raises questions about how best to identify the unique factors that contribute to individual variation in processing speed performance. We have used a structural covariance approach for analyzing brain morphology data, described below, with the goal of identifying putative neural systems that most contribute to processing speed declines. This review (1) summarizes the extant literature that links processing speed to neuroanatomical variation, with an emphasis on (2) our independent component analysis (ICA) or source based morphometry findings for evidence of two specific patterns of frontal and cerebellar structural covariance, and (3) proposes functional neural systems that may underlie the processing speed declines that older adults experience.

\section{NEUROBIOLOGICAL PREDICTORS OF PROCESSING SPEED}

Readers of this review should consider that many age-related processing speed findings reported in the literature are cross-sectional in nature, including the primary findings reviewed here. This is important because there are developmental (Laasonen et al., 2002; Deary et al., 2010) and sampling factors that could affect the outcome of cross-sectional studies on processing speed. In addition, the neural systems that are critical for understanding individual variation in cognition may differ across the lifespan (Zimmerman et al., 2006). There may be qualitative neurobiological changes that distinguish older adults from the oldest adults. Our approach has been to include adults across the lifespan because cognitive aging appears to begin when people reach 20-30 years of age (Salthouse, 2009). For this reason, we consider many of the findings summarized in this review to reflect effects of chronological age. Importantly, however, longitudinal findings of processing speed change have supported the robust cross-sectional findings of processing speed declines on cognitive function (Finkel et al., 2009). We anticipate that neural systems exhibiting cross-sectional processing speed changes will also exhibit robust within subject changes with processing speed.

\section{A BRIEF HISTORY AND GLOBAL CORTICAL DECLINES}

One early neurobiological explanation for agerelated changes in processing speed focused on cortical declines in neuropil (Morris and McManus, 1991). Age-related differences in total gray matter volume have been related to differences in processing speed (Chee et al., 2009), which theoretically could result in degraded or noisy representations that would slow the recognition of stimuli and decision making. For example, primary auditory cortex neurons in the aged rat exhibit elevated excitation that has been related to a loss of GABAergic function (Caspary et al., 2008). These changes likely stem from reduced inhibitory interneuron input onto dendritic arbors that are diminished in the aged rat (Vaughan, 1977) and in older adult human auditory association cortex (Jacobs and Scheibel, 1993). Similar changes could occur across perceptual, planning, and motor systems that support speeded task performance. Thus, age-related changes in cognition are likely to be driven by changes in the connectivity of neural systems (Dickstein et al., 2007).

Another prominent explanation for processing speed declines is that a loss of myelination could slow conduction rates and therefore slow processing speed (Morris and McManus, 1991; Fjell and Walhovd, 2010). Age-related differences in whole brain white matter fractional anisotropy have been associated with processing speed (Coffey et al., 2001; Charlton et al., 2006; Vernooij et al., 2008; Schiavone et al., 2009), although this variation likely reflect a loss of myelinated axons. There is a myelin-specific explanation that could account for age-related changes in processing speed. The number of oligodendrocytes does not decline with age in the rhesus monkey and 
have been observed to re-myelinate axons whose oligodendrocytes have died (Peters, 2009). The consequence, however, is (1) a shortening in the lengths of the new myelin sheaths, (2) additional nodes of Ranvier that could alter conductance speed, and (3) the potential for altered neural firing patterns that could further diminish the quality of neural signals affected by axonal and neuropil loss (Peters, 2009).

The early hypotheses for processing speed decline focused on global changes in gray and white matter, due in part to the available evidence. Over the last 20 years there has been mounting evidence for regional specificity in the severity of age-related change in gray matter volume. While nearly the entire brain exhibits reduced volume with age (Brickman et al., 2008; Chee et al., 2009; Fjell et al., 2009), anterior insula, inferior frontal, superior frontal, medial frontal, and cerebellar regions exhibit some of the most pronounced changes with age when measured with automated (Good et al., 2001; Resnick et al., 2003; Salat et al., 2004; Tisserand et al., 2004; Lemaitre et al., 2005; Chee et al., 2009) and manual measures (Raz et al., 1997, 2005, 2010; Jernigan et al., 2001; Tisserand et al., 2002; DeCarli et al., 2005; Raz and Rodrigue, 2006). Given the substantial changes in frontal white matter that also occur with age (Bendlin et al., 2010; Giorgio et al., 2010; Westlye et al., 2010), these results suggest that frontal cortex is undergoing de-afferentation and subsequent decline with increasing age. We return to this premise below with respect to vascular explanations for changes in processing speed. One important point is that these findings could explain why frontal cortex exhibits fewer functional connections with other cortical and sub-cortical regions in older compared to younger adults (Meunier et al., 2009), with reduced control of sensory and perceptual processing. Similarly, the cerebellar hemispheres could be considered as having domain general roles in the support of cognitive function, where the substantial aging effects on morphology (Raz et al., 2010) could affect perceptual and cognitive task performance. Perhaps because of their widespread influence on behavior, frontal and cerebellar regions are consistently related to a variety of speeded or timed cognitive tasks. This review focuses on frontal and cerebellar associations with processing speed.

\section{FRONTAL CORTEX AND PROCESSING SPEED}

Frontal cortex has been a primary target for the study of age-related processing speed changes because of the relatively pronounced aging effects on frontal cortex morphology and interest in prominent hypotheses for cognitive aging such as the Frontal Aging Hypothesis (West, 1996) and the Inhibition Deficit Hypothesis (Hasher and Zacks, 1988; Hasher et al., 1999). Volumetric, voxel-based, and sulcal morphometry examinations of frontal gray matter have demonstrated associations with performance across a wide variety of cognitive tasks. Importantly, the frontal gray matter findings appear to be dependent on the susceptibility of frontal white matter to age-related decline.

Regions of frontal gray matter that exhibit cross-sectional change with age and predict processing speed are presented in Figure 1 from a sample of 42 adults that ranged in age from 19 to 79 years (Eckert et al., 2010). Younger adults with elevated medial frontal and lateral frontal gray matter volume demonstrated faster processing speed compared to older adults with lower gray matter volume in these regions. This pattern of frontal results is consistent with volumetric and voxel-based gray matter associations with processing speed that were observed in a sample of 248 subjects ranging in age from 55 to 86 years (Chee et al., 2009). Similarly, the volume of prefrontal cortex has been observed to predict a drawing speed (Kennedy and Raz, 2005), an estimate of perceptual comparison speed (Schretlen et al., 2000), and a measure of fluid intelligence in older adults (Raz et al., 2008; Kennedy et al., 2009). Frontal sulcal span, an indirect measure of gray matter declines in frontal cortex, has also been associated with processing speed (Kochunov et al., 2010).

Individual variation in prefrontal gray matter volume among older adults is strongly related to frontal white matter volume (Raz et al., 2003). Perhaps then it is not surprising that multiple measures of frontal white matter morphology or integrity have been associated with processing speed, including transverse relaxation rate (Bartzokis et al., 2010), midline genu area of the corpus callosum (Jokinen et al., 2007), and fractional anisotropy and/or mean diffusivity (Deary et al., 2006; Grieve et al., 2007; Bucur et al., 2008; Kennedy and Raz, 2009a; Schiavone et al., 2009; Bendlin et al., 2010; Kochunov et al., 2010; Penke et al., 2010). An example of the robust association between fractional anisotropy in frontal lobe white matter and processing speed is presented in Figure 2. Individual variation in frontal lobe fractional anisotropy has been related to processing speed in healthy young adults (Turken et al., 2008), suggesting the interesting possibility that aging exaggerates normal structure - function associations (Harris et al., 2009).

A large body of literature implicates white matter pathology in the cognitive slowing of older 


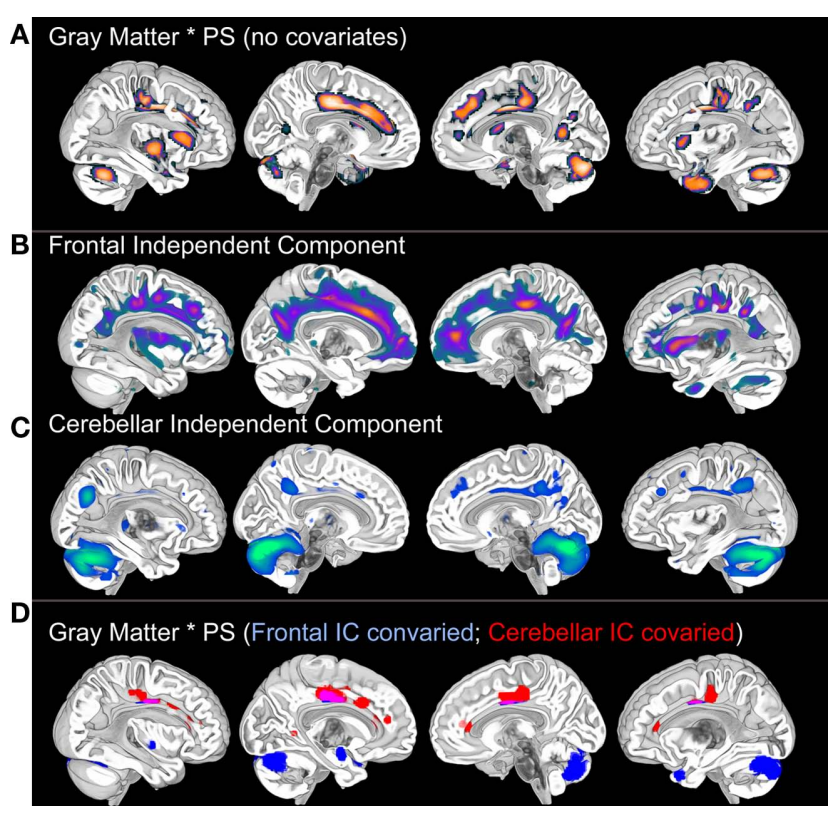

FIGURE 1 | Voxel-based gray matter variation (modulated) predicts Connections Simple processing speed performance (A). These results are not significant at the $p<0.001$ (uncorrected) level after controlling for age, thereby demonstrating the dependence of the results on age. Posterior cingulate, cuneus, cerebellar, and medial temporal regions exhibited weak associations with processing speed ( $p<0.05$, uncorrected) after controlling for age, suggesting that age may exaggerate normal variation in brain morphology and processing speed. SBM (please see Figure $\mathbf{3}$ for an SBM summary) demonstrates unique patterns of frontal and cerebellar gray matter variance $\mathbf{( B , C )}$ that each accounted for different distributions of the processing speed results [(D): $p<0.001$ after controlling for variance representing either the frontal or the cerebellar independent components]. Importantly, by controlling for either gray matter component we can see that there are at least two sources that contribute to the association between gray matter and processing speed in this sample. In a separate analysis, these component specific effects were not significant using a $p<0.001$ threshold when age was covaried. There were weak $p<0.05$ associations with processing speed in cingulate and cerebellar regions after controlling for either component and age, again suggesting the influence of additive developmental factors (Deary et al., 2010). Results displayed on the MNI template. PS, processing speed; SBM, source based morphometry.

adults (Gunning-Dixon and Raz, 2000; Kennedy and Raz, 2009b; Vernooij et al., 2009; Kochunov et al., 2010; Vidal et al., 2010; please see GunningDixon et al., 2009 for additional review). White matter hyperintensities, a common age-related finding in periventricular regions (Almkvist et al., 1992; Soderlund et al., 2003; Cook et al., 2004), have a gradual impact on cognition over time (Silbert et al., 2009) and appear to affect regional gray matter morphology even before overt cognitive changes are observable (Ota et al., 2010). They are generally considered to be a sign of cerebral small vessel disease and the severity of the hyperintensities has been related to hypertension (Brickman et al., 2010), blood pressure (Kochunov et al., 2010; Kuo et al., 2010), coronary artery calcification (Vidal et al., 2010), and endothelial dependent vasodilation (Hoth et al., 2007).

White matter pathology has been observed independently of effects related to systolic blood pressure and cholesterol (Chowdhury et al., in press) suggesting that multiple mechanisms can produce white matter damage. Age-related changes in pericytes, cells that contribute to the blood brain barrier, may provide an explanation for both hypoxia related damage and neurotoxic damage stemming from microvessel leakage. Pericyte deficient mice exhibit progressive loss of cerebral perfusion and a loss of dendritic spines that has been attributed to the leakage of damaging proteins through the blood brain barrier and subsequent neuronal loss (Bell et al., 2010). Both conditions would produce an inflammatory response and could explain why variation in interleukin-6 has been associated with changes in macaque frontal white matter (Willette et al., 2010). Regardless of the mechanism, damage to periventricular white matter appears to disrupt pathways projecting to and from frontal lobe regions that support performance on processing speed tasks.

\section{CEREBRO-CEREBELLAR AND PROCESSING SPEED DECLINES}

Cerebellar morphology also undergoes robust age-related structural change but has not received the same experimental attention as frontal cortex 


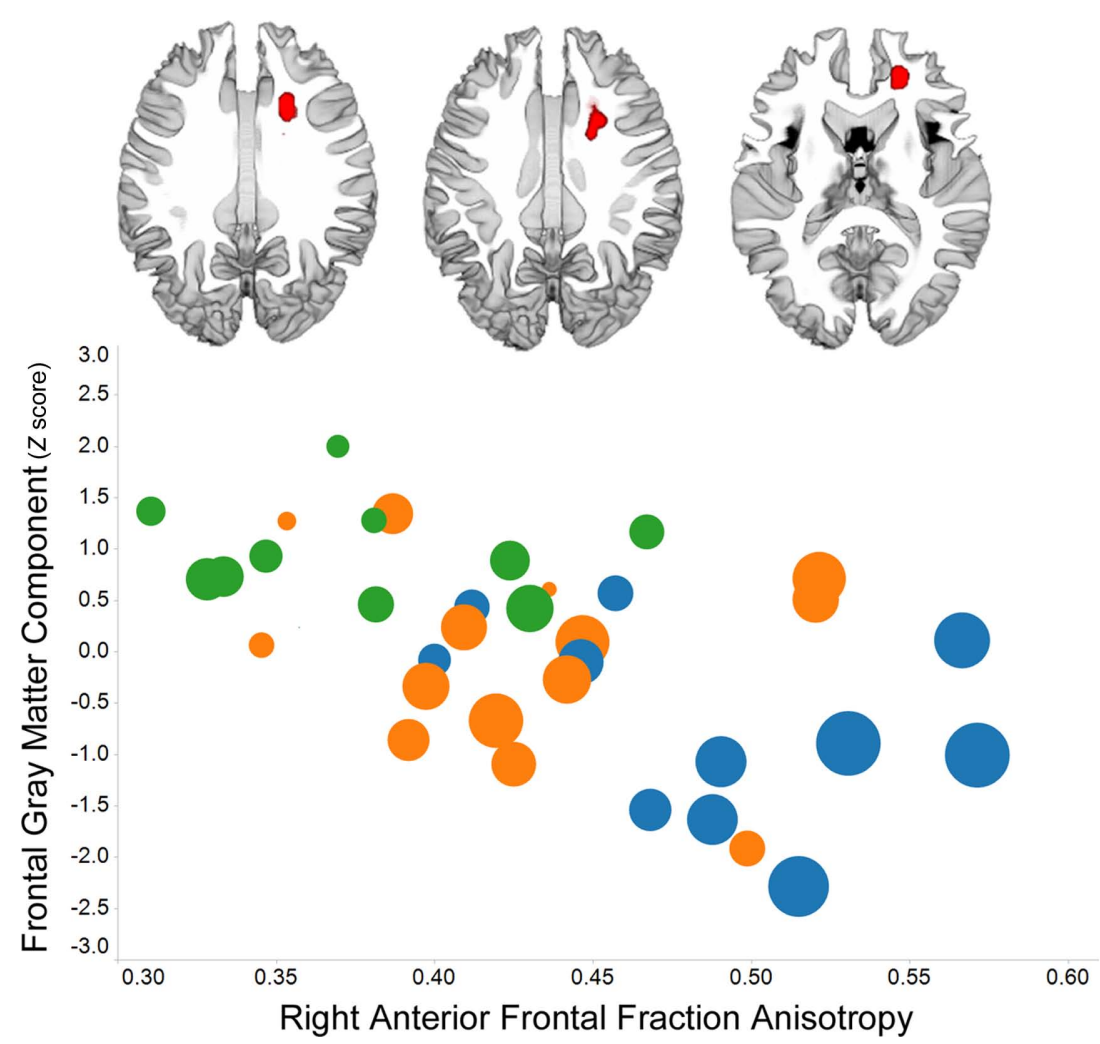

FIGURE 2 | Voxel-based analysis of fractional anisotropy data demonstrates a right frontal association with Connections Simple processing speed ( $p<0.01$, family-wise discovery rate corrected) in 36 of the 42 subjects whose data were included in the Figure 1 analyses. The graph shows the association between frontal fractional anisotropy and the frontal gray matter component from Figure 1, the presence of white matter hyperintensities among people with low fractional anisotropy and low frontal gray matter (circle color: no hyperintensities - blue; some hyperintensities - orange; pronounced hyperintensities - green), and that PS is related to each of these variables (larger circle size reflects faster processing speed). (The TSPOON approach designed to control for smoothing kernel effects, Lee et al., 2009, was used to process the $2 \mathrm{~mm} \times 2 \mathrm{~mm}$ in plane resolution images that were collected on a Philips 3 T with 32 directions using an 8-channel phased array head coil. The B0 and FA data were co-registered to each subject's T1 image and then normalized into study-specific space using the DARTEL parameters obtained for the T1 images.)

with respect to age-related changes in processing speed. This is due, in part, to image processing choices that exclude the cerebellum and because the prominent theories of cognitive aging (the Frontal Aging Hypothesis and the Inhibition Deficit Hypothesis) focus on frontal cortex. While there may be a publication bias related to negative findings, relations between cerebellar morphology and processing speed have been observed and provide support for a fronto-cerebellar aging hypothesis (Hogan, 2004).

Hogan (2004) proposed that changes in feedback and feedforward cerebro-cerebellar interaction result in greater within subject variation in task performance, reduced behavioral automaticity, and increased demands on cognitive control, as well as reduced working memory capacity. This hypothesis is based on normative and patient evidence linking the cerebellum to cognitive and perceptual functions (e.g., Eckert et al., 2003; Chen and Desmond, 2005; Desmond et al., 2005; Steinlin, 2007) and its distinct patterns of structural and functional connectivity with motor, sensory, and attention-related cortical regions (e.g., Kelly and Strick, 2003; Habas et al., 2009; Krienen and Buckner, 2009; Schmahmann, 2010). In particular, limits on the cerebellum's role in modifying motor function in response to sensory and perceptual feedback (Ivry, 1997) could affect performance on perceptual and motor processing speed tasks.

Cross-sectional age-related changes in cerebellar morphology have been associated with processing speed (MacLullich et al., 2004; Paul et al., 2009; Eckert et al., 2010) and a measure of general intelligence among older adults (Hogan et al., 2011). In particular, we observed that processing speed was predicted by regional 
cerebellar gray matter volume (Figure 1). This voxel-based effect was present throughout the vermis and cerebellar hemispheres (superior to the horizontal fissure). The vermis finding is spatially consistent with a finding that the midline surface area of vermis (declive, folium, tuber region) predicted age-related Digit-Symbol Substitution Test performance, which was significant even after controlling for an estimate of intracranial volume (MacLullich et al., 2004). In addition, a volumetric measure of the same vermis region and total cerebellar gray matter volume were significantly related to age-related changes in Trail Making Test (alternating condition) performance (Paul et al., 2009). In the Paul et al. (2009) study, however, the vermis measure did not significantly predict Trail Making Task performance after accounting for a measure of prefrontal volume (Brodmann areas 9 and 46). The specificity of these frontal and cerebellar findings is addressed below.

As suggested by Hogan (2004), the processing speed and cerebellar findings could be explained by problems with sensory - motor integration. For example, a history of falling and slow processing speed has been associated with delayed horizontal saccades during the initiation of a footlift for a stepping task (Greany and Di Fabio, 2008). In addition, left cerebellar volume has been related to gait speed in older adults (Rosano et al., 2007; although see Rosano et al., 2008) and right cerebellar hemisphere volume has been associated with balance difficulty among older adults (Rosano et al., 2007). A sensory-motor integration explanation could also explain why cerebellar volumes have been associated with perceptual motor skill as measured by total time on target for a pursuit rotor task (Raz et al., 2000), although not for a timed mirror tracing task (Kennedy and Raz, 2005). Age-related differences in cerebellar volume has also been significantly correlated with associative learning as measured by eye-blink conditioning (Woodruff-Pak et al., 2000, 2001). Together, these findings suggest that the behavioral effects of cerebellar aging are variable across subjects, perhaps because of individual variability in developmental factors (Deary et al., 2010), and may have widespread effects on a variety of cerebellar functions.

Based on the perceptual motor skill associations with cerebellar morphology, we asked whether performance on the Connections processing speed test could be influenced by increasing performance across the two trials of each sub-test [numbers only, letters only, numbers - letters (starting with numbers), letters numbers (starting with numbers)]. There was no evidence indicating that people with elevated cerebellar gray matter exhibited the greatest improvement in performance across the trials. In fact, there was weak evidence for the opposite effect. People with low cerebellar gray matter volume were more likely to improve across the first to second trials of the alternating letters - numbers condition compared to people with elevated cerebellar gray matter volume $(p<0.05$ uncorrected; no significant relations were seen for the other Connections conditions). This finding suggests that the processing speed and cerebellar relation was not due to a specific learning effect, however it is possible that we could not detect evidence of procedural learning because of (1) the balanced order in which the sub-tests are administered or (2) ceiling effects on the first trial of the Connections sub-tests in people with the greatest cerebellar gray matter volume. Importantly, however, these results are consistent with evidence that variation in cerebellar morphology is related to the initial stages of skill acquisition (Raz, 2000).

Returning to the Hogan (2004) cerebellar hypothesis for cognitive aging, we also wondered whether variation in performance across the Connections tests could be related to age and cerebellar morphology. A measure of each subject's variance in processing speed was obtained from the SD of subject $Z$ scores from the Connections sub-tests, where the $Z$ score was based on the mean performance of the sample for each subtest. Rather than greater variability among the oldest subjects, an inverted $U$ function was observed where by middle-aged subjects exhibited the most variable Connections performance (age $\times$ Connections variance; quadratic $r=0.41$, $p<0.05$; linear $r=-0.05$, ns). There were not clear linear or non-linear relations with cerebellar morphology and the Connections variance measure, but it is intriguing to consider that elevated variance in performance among middle-aged subjects may be an early behavioral marker for neurobiological declines that slow processing speed and cognition.

Finally, there are questions about the etiological factors that drive age-related cerebellar changes and that would contribute to slowed processing speed. We observed that cerebellar associations with processing speed occurred independently of periventricular white matter hyperintensities, suggesting that cerebral small vessel disease was not a primary factor for changes in cerebellar morphology in our sample. Similarly, white matter hyperintensities did not account for the association between cerebellar volume and gait speed observed in the Rosano et al. (2007) study. The results of other studies, however, have indicated that primary declines in prefrontal cortex 
contribute to cerebellar changes in morphology (Bugalho et al., 2007) that predict processing speed (Paul et al., 2009).

There is the strong likelihood that cerebellar and frontal regions vary in susceptibility to different age-related risk factors. The high metabolic demands of cerebellar Purkinje cells, which demonstrate a substantial loss in number with age (Hall et al., 1975; Andersen et al., 2003), may increase the risk for cell death due to oxidative stress. Indeed, oxidative stress is one factor contributing to cerebellar aging in mice (Lee et al., 2000). The results of human imaging studies indicate that leptin may serve to protect against oxidative stress based on evidence that plasma concentration of leptin was associated with elevated cerebellar and hippocampal gray matter in middle-aged and older adults (Narita et al., 2009) and evidence that leptin treatment increases cerebellar gray matter in leptin deficient patients (Matochik et al., 2005). These findings, together with developmental findings in C57 mice showing that leptin promotes cerebellar Purkinje cell survival and neurite outgrowth (Oldreive et al., 2008), suggest the interesting possibility that leptin limits the impact of oxidative stress on cerebellar Purkinje cells whose high metabolic rate places them at risk for age-related declines as it does for in vitro hippocampal Purkinje cells (Guo et al., 2008). This leptin explanation for cerebellar health is just one example for what is likely a multifactorial aging process in the cerebellum.

\section{IDENTIFYING UNIQUE PATTERNS OF CEREBRAL AGING}

The review above suggests that age-related changes across multiple systems could affect processing speed. The frontal findings, in particular, could explain why changes in auditory gap detection (Harris et al., 2010) and tactile temporal order thresholds (Craig et al., 2010) have been related to visual-motor measures of processing speed. It is difficult to determine, however, from the results presented in Figure 1A whether widespread anatomical effects stem from a common mechanism or whether unique neural systems are affected. This is a particularly significant problem for cross-sectional chronological aging studies where disentangling neurobiological patterns of aging can be difficult. Our approach to addressing this challenge has been to use ICA or source based morphometry to identify unique patterns of structural covariance in the data that uniquely predict age-related differences in processing speed and that might provide insight into the affected neural systems.
Independent component analysis of functional imaging data is helping to identify consistent patterns of neural activity across experiments that are thought to reflect distinct neural systems for focused and scanning attention, motor function, or auditory and visual processing (Beckmann et al., 2005; Eckert et al., 2008a). Indeed, this type of analysis may help to identify atypical coherence in neural systems that underlie changes in processing speed. For example, the ability to switch between functional networks that are thought to represent focused attention to a task (dorsal attention network; Sridharan et al., 2007) and self-referential thinking (default mode network; Andrews-Hanna et al., 2010) has been related to within subject variability in children's task performance (Kelly et al., 2008), appears to be impaired in older adults (Grady et al., 2006), and may also relate to variable processing speed performance in middle-aged adults.

Independent component analysis of structural MRI data has been described as source based morphometry because unique patterns of variation are thought to have common underlying influences or sources (Xu et al., 2009; Figure 3). Specific regions of gray matter may covary across subjects because of variation in fiber pathways connecting distant areas, the amount of neuropil, vascular support, or image artifact. For example, this technique identified periventricular white matter regions where white matter hyperintensities were observed (Figure 6 in Eckert et al., 2010). In addition, the component included regions where there was less gray matter in frontal cortex (IC7, Figure 3). This result suggested that a common source, presumably cerebral small vessel disease, was affecting gray and white matter segmentation in people with reduced frontal gray matter and lower fractional anisotropy in frontal white matter.

The source based morphometry analysis also identified six other independent spatial patterns of gray matter covariance (Figure 3). We identified multiple patterns of gray matter variation that were related to age but only some were related to processing speed. One component coincided spatially with the default mode network (IC1), which was nearly perfectly correlated with total brain volume $(r=0.90, p<0.001)$, related to age $(r=-0.34, p<0.05)$, but not uniquely predictive of processing speed. The frontal component (IC7) related to vessel disease and a cerebellar component (IC4) were each associated with age and uniquely predicted processing speed (Figures 1 and 3). Importantly, unique frontal-cerebellar predictors of processing speed were identified with this analysis. 


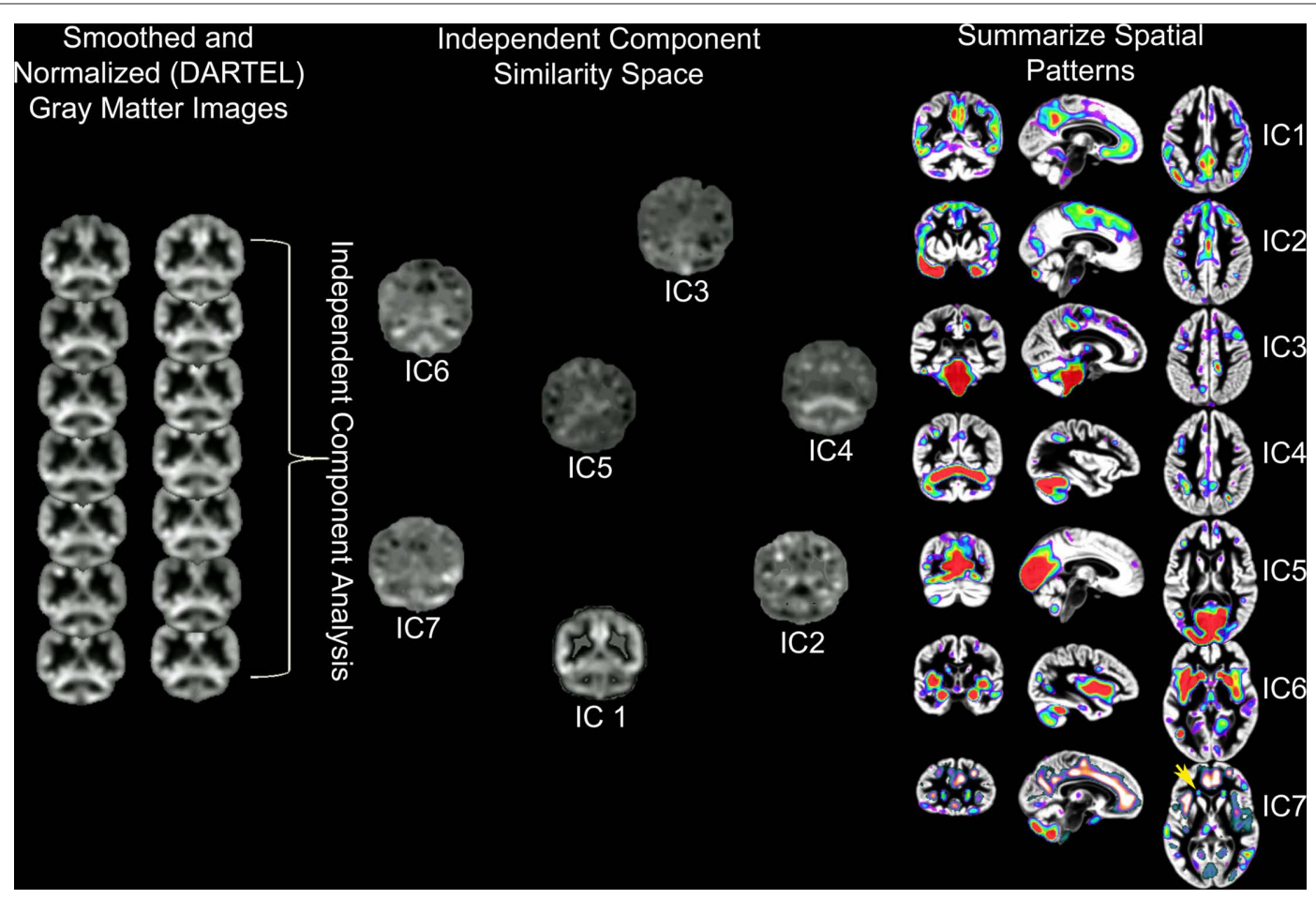

FIGURE 3 | Source based morphometry or ICA of gray matter probability images across $\mathbf{4 2}$ subjects. Each subject's T1-weighted image is segmented to generate a gray matter probability image that is normalized to a common coordinate space and smoothed. ICA is performed across the sample of gray matter images. The degree to which each independent component (IC) or unique pattern of variance can be compared to the other ICs with a variety of metrics, including an estimate of similarity space. The brain regions that contribute most to each component can be identified by displaying each component with scaled intensity values ( $Z$ score $=1-3$ above). Each IC also has an inverse component or regions that are negatively correlated with regions in the IC. An example is presented for $\mathrm{IC} 7$ where white matter hyperintensity related segmentation error (yellow arrow) is identified by ICA and is inversely correlated with decreased frontal gray matter (e.g., anterior cingulate, anterior insula, and superior frontal sulcus regions represented by hot signal intensities above). ICs 4 and 7 are discussed below and were uniquely related to processing speed. This is important because these results suggest there are independent age-based sources that affect gray matter variation in cerebellar (IC4) and frontal (IC7) regions that are associated with processing speed.
A nice feature of the source based morphometry approach is that each component can be covaried in a whole brain analysis to identify regions uniquely associated a variable of interest. This type of analysis is presented in Figure $\mathbf{1}$ and demonstrates: (1) that the frontal and cerebellar regions were uniquely predictive of processing speed; (2) the spatial extent of these effects; and (3) that some brain regions were significantly correlated with processing speed after controlling for either component. The latter is a particularly exciting demonstration of the potential for source based morphometry as an analytical tool because some of these regions, the cingulate for example, had voxels that were influenced by both the source of the frontal component and the source of the cerebellar component. In other words, this is like height being influenced by iodine deficiency and parental height, but in this case the gray matter volume of a specific brain region appears to be influenced by multiple additive aging risk factors. Figure 4 provides a summary of these results, pre- sented in the context of the multifactorial nature cognitive aging.

\section{TOWARD A SYSTEMS UNDERSTANDING OF AGE-RELATED CHANGES IN PROCESSING SPEED}

The structural components that we identified with source based morphometry included patterns of variation that have been observed in functional imaging studies using ICA (Beckmann et al., 2005; Damoiseaux et al., 2006; De Luca et al., 2006; Habas et al., 2009). These results suggested that source based morphometry could be used to identify structural variation that corresponds to functionally defined neural systems. Although source based morphometry results will be dependent on variation within a sample, further support for the potential of the source based morphometry approach to identify neural systems was the observation that individual variation in a cerebellar component was related to individual variation in a white matter 


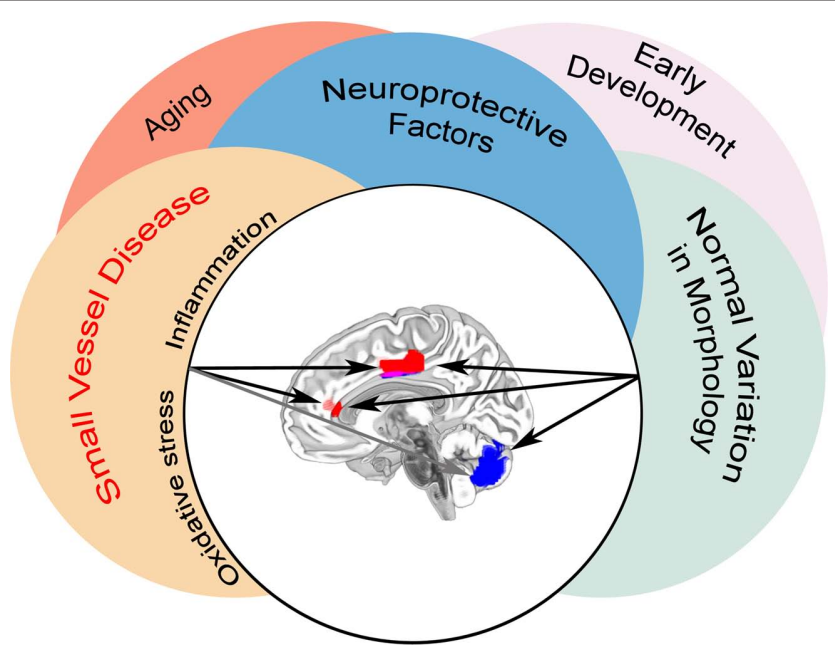

FIGURE 4 | Summary of potential factors affecting frontal and cerebellar morphology and processing speed. On the left side of the figure, aging affects brain morphology through the damaging effects of oxidative stress and inflammation (small vessel disease is in red because of consistent evidence linking cerebral small vessel disease to structural declines and slowed processing speed). These detrimental effects are likely buffered by neuroprotective factors such as (1) leptin and growth factor levels that limit the impact of oxidative stress, (2) norepinephrine or blueberry limits on inflammatory responses in animal models (Heneka et al., 2010; Willis et al., 2010), (3) neurotrophic factors (Kim et al., in press; Raz et al., 2009), and (4) positive lifestyle behaviors such as aerobic exercise (Rosano et al., 2010; Voss et al., 2010). The gray arrow indicates that oxidative stress and inflammation likely affects cerebellar morphology, in comparison to the black arrows for which there is empirical evidence of significant associations. The right side of the figure is designed to emphasize that early development has a significant influence on the degree to which older adults will demonstrate atypical morphology and impaired processing speed (Deary et al., 2006, 2010), but could also influence the expression of neuroprotective factors and the development of lifestyle patterns of behavior and modulate risk for age-related neural declines. While this summary figure is general in nature, it is designed to emphasize the multifactorial and interactive effects of aging neural systems on processing speed.

component that included the middle cerebellar peduncles, cerebral peduncles, and posterior limb of the internal capsule (Figure 5 in Eckert et al., 2010). The possibility that source based morphometry captures variance reflecting neural systems may therefore provide some insight into the neural systems that influence processing speed.

Our results and the existing literature suggest that a dorsal attention (Sweeney et al., 2001) or prefrontal-mediated system for maintaining focused attention, inhibitory control, and working memory is significantly affected by microvascular damage. This interpretation is consistent with evidence that prefrontal gray matter volume has been related to perseveration on the Wisconsin Card Sorting Task (Raz et al., 2003, 2008). It is important, however, to note that our processing speed results were most pronounced for the Connections Simple test compared to the Connections Complex task that required inhibiting a previous response.

Older adults may become particularly dependent on prefrontal cortex to maintain normal performance when age-related declines in sensory systems make relatively easy tasks more chal- lenging because of degraded stimulus representations (Eckert et al., 2008b). Indeed, elevated frontal activity is a common finding in functional imaging studies of aging (Cabeza et al., 2002; Grady et al., 2005) and appears to reflect compensatory engagement of frontal cortex in some studies (Townsend et al., 2006). Performance across a variety of tasks may slow or exhibit impairment with subsequent declines in a dorsal attention system, particularly for tasks that require sustained attention or the inhibition of distracting information. For this reason, changes in a dorsal attention system could account for slowed processing speed across sensory domains.

Interestingly, the dorsal attention system appears to include regions of the cerebellar hemispheres (Krienen and Buckner, 2009). The frontal and cerebellar gray matter components observed in Eckert et al. (2010) did exhibit some spatial overlap even though they each predicted additive variance in those overlapping regions. It is possible that primary aging effects are occurring across the dorsal attention system, but are differentially concentrated across people. This could explain why cerebellar measures might be uniquely predictive of processing speed in some 
studies and not others. The same neural system may be affected, but there may be regional specificity in the degree to which it is affected.

Changes in a dorsal attention or executive attention system could also explain why older adults exhibit difficulty inhibiting attention, as measured by eye-movements, to distracting or irrelevant visual targets (Kramer et al., 1999). This would have the downstream effect of slowing performance because of difficulty making a saccade to a new target, a function that is critical for many processing speed tasks. It is also possible that direct effects on an eye-movement system could influence processing speed, which is suggested by our findings that processing speed covaries with gray matter variation in the frontal eye-fields, cingulate, dorsolateral prefrontal cortex, and vermis (Fujikado and Noda, 1987; Hayakawa et al., 2002; Ploner et al., 2005). Older adults have been observed to exhibit impaired horizontal saccades (Carter et al., 1983; Sharpe and Zackon, 1987), but not in every study (Pratt et al., 2006). Understanding the degree to which frontal and cerebellar declines relate to horizontal saccade performance may provide insight into the statistical linkage between neuroanatomical variation in these regions and processing speed.

Cerebellar morphology associations with processing speed most likely reflect a change in the ability of the cerebellum to integrate sensory and motor information to help guide smooth and quick movements. Impaired integration of visual and proprioceptive information because of granule cell loss and/or impaired output of this information because of Purkinje cell loss could slow behavior and increase movement errors. This prediction is supported by evidence that older adults have difficulty stopping arm movements smoothly and make more corrective movements during reaching than younger adults (Brown, 1996). It is unclear, however, whether specific cerebellar zones and related function are affected because of the widespread cerebellar vermis and hemisphere effects observed in MRI studies (Figure 1).

In summary, the existing literature and our SBM findings strongly implicate a dorsal attention system in the processing speed declines of older adults. Impaired function of a domain general system would account for slowed task performance across such a wide variety of behavioral tasks. Questions remain how best to enhance healthy aging of this system, although exercise appears to have positive benefits (Colcombe et al., 2003; Rosano et al., 2010). In addition, the degree to which cerebellar declines reflect impairments in specific cerebellar systems and/or reflect changes in a dorsal attention system is unclear. Addressing these questions and identifying the mechanisms for declines in neural systems that support processing speed has the potential to enhance healthy cognitive aging.

\section{ACKNOWLEDGMENTS}

I thank the participants who have contributed to our research. This work was supported by the National Institute on Deafness and other Communication Disorders (P50 DC00422) and was conducted in a facility constructed with support from Research Facilities Improvement Program (C06 RR14516) from the National Center for Research Resources, while Mark Eckert was an American Federation for Aging Research Grant recipient.

\section{REFERENCES}

Almkvist, O., Wahlund, L. O., AnderssonLundman, G., Basun, H., and Backman, L. (1992). White-matter hyperintensity and neuropsychological functions in dementia and healthy aging. Arch. Neurol. 49, 626-632.

Andersen, B. B., Gundersen, H. J., and Pakkenberg, B. (2003). Aging of the human cerebellum: a stereological study. J. Comp. Neurol. 466, 356-365.

Andrews-Hanna, J. R., Reidler, J. S., Sepulcre, J., Poulin, R., and Buckner, R. L. (2010). Functional-anatomic fractionation of the brain's default network. Neuron 65, 550-562.

Bartzokis, G., Lu, P. H., Tingus, K., Mendez, M. F., Richard, A., Peters, D. G., Oluwadara, B., Barrall, K. A., Finn, J. P., Villablanca, P., Thompson, P. M., and Mintz, J. (2010). Lifespan trajectory of myelin integrity and maxi- mum motor speed. Neurobiol. Aging 31, 1554-1562.

Beckmann, C. F., DeLuca, M., Devlin, J. T., and Smith, S. M. (2005). Investigations into resting-state connectivity using independent component analysis. Philos. Trans. R. Soc. Lond., B, Biol. Sci. 360, 1001-1013.

Bell,R.D., Winkler,E.A., Sagare,A.P., Singh, I., Larue, B., Deane, R., and Zlokovic, B. V. (2010). Pericytes control key neurovascular functions and neuronal phenotype in the adult brain and during brain aging. Neuron 68, 409-427.

Bendlin, B. B., Fitzgerald, M. E., Ries, M. L., Xu, G., Kastman, E. K., Thiel, B. W., Rowley, H. A., Lazar, M., Alexander, A. L., and Johnson, S. C. (2010). White matter in aging and cognition: a crosssectional study of microstructure in adults aged eighteen to eighty-three. Dev. Neuropsychol. 35, 257-277.
Brickman, A. M., Reitz, C., Luchsinger, J. A., Manly, J. J., Schupf, N., Muraskin, J., DeCarli, C., Brown, T. R., and Mayeux, R. (2010). Long-term blood pressure fluctuation and cerebrovascular disease in an elderly cohort. Arch. Neurol. 67, 564-569.

Brickman, A. M., Schupf, N., Manly, J. J. Luchsinger, J.A.,Andrews, H., Tang, M. X., Reitz, C., Small, S. A., Mayeux, R. DeCarli, C., and Brown, T. R. (2008). Brain morphology in older African Americans, Caribbean Hispanics, and whites from northern Manhattan Arch. Neurol. 65, 1053-1061.

Brown, S. (1996). “Control of simple arm movements in the elderly," in Changes in Sensory Motor Behavior in Aging, eds A. Ferrandez and N. Teasdale (Amsterdam: Elsevier Science), 27-52.

Bucur, B., Madden, D. J., Spaniol, J. Provenzale, J. M., Cabeza, R., White,
L. E., and Huettel, S. A. (2008). Agerelated slowing of memory retrieval: contributions of perceptual speed and cerebral white matter integrity. Neurobiol. Aging 29, 1070-1079.

Bugalho, P., Viana-Baptista, M., Jordao, C., Secca, M. F., and Ferro, J. M. (2007). Age-related white matter lesions are associated with reduction of the apparent diffusion coefficient in the cerebellum. Eur. J. Neurol. 14, 1063-1066.

Cabeza, R., Anderson, N. D., Locantore, J. K., and McIntosh, A. R. (2002). Aging gracefully: compensatory brain activity in high-performing older adults. Neuroimage 17, 1394-1402.

Carter, J. E., Obler, L., Woodward, S., and Albert, M. L. (1983). The effect of increasing age on the latency for saccadic eye movements. J. Gerontol. 38, 318-320. 
Caspary, D. M., Ling, L., Turner, J. G., and Hughes, L. F. (2008). Inhibitory neurotransmission, plasticity and aging in the mammalian central auditory system. J. Exp. Biol. 211(Pt 11), 1781-1791.

Charlton, R. A., Barrick, T. R., McIntyre, D. J., Shen, Y., O'Sullivan, M., Howe, F. A., Clark, C. A., Morris, R. G., and Markus, H. S. (2006). White matter damage on diffusion tensor imaging correlates with age-related cognitive decline. Neurology 66, 217-222.

Chee, M. W., Chen, K. H., Zheng, H., Chan, K. P., Isaac, V., Sim, S. K., Chuah, L. Y., Schuchinsky, M., Fischl, B., and Ng, T. P. (2009). Cognitive function and brain structure correlations in healthy elderly East Asians. Neuroimage 46, 257-269.

Chen, S. H., and Desmond, J. E. (2005). Temporal dynamics of cerebro-cerebellar network recruitment during a cognitive task. Neuropsychologia 43, 1227-1237.

Chowdhury, M. H., Nagai, A., Bokura, H., Nakamura, E., Kobayashi, S., and Yamaguchi, S. (in press). Age-related changes in white matter lesions, hippocampal atrophy, and cerebral microbleeds in healthy subjects without major cerebrovascular risk factors. J. Stroke Cerebrovasc. Dis.

Coffey, C. E., Ratcliff, G., Saxton, J. A., Bryan, R.N., Fried, L. P., and Lucke, J.F. (2001). Cognitive correlates of human brain aging: a quantitative magnetic resonance imaging investigation. $J$. Neuropsychiatry Clin. Neurosci. 13, 471-485.

Colcombe, S. J., Erickson, K. I., Raz, N., Webb, A. G., Cohen, N. J., McAuley, E., and Kramer, A. F. (2003). Aerobic fitness reduces brain tissue loss in aging humans. J. Gerontol. A Biol. Sci. Med. Sci. 58, 176-180.

Cook, I. A., Leuchter, A. F., Morgan, M. L., Dunkin, J. J., Witte, E., David, S., Mickes, L., O'Hara, R., Simon, S., Lufkin, R., Abrams, M., and Rosenberg, S. (2004). Longitudinal progression of subclinical structural brain disease in normal aging. Am. J. Geriatr. Psychiatry 12, 190-200.

Craig, J. C., Rhodes, R. P., Busey, T. A., Kewley-Port, D., and Humes, L. E. (2010). Aging and tactile temporal order. Atten. Percept. Psychophys. 72, 226-235.

Damoiseaux,J.S., Rombouts,S.A., Barkhof, F., Scheltens, P., Stam, C. J., Smith, S. M., and Beckmann, C.F. (2006). Consistent resting-state networks across healthy subjects. Proc. Natl. Acad. Sci. U.S.A. 103, 13848-13853.

De Luca, M., Beckmann, C. F., De Stefano, N., Matthews, P. M., and Smith, S. M. (2006). fMRI resting state networks define distinct modes of long-distance interactions in the human brain. Neuroimage 29, 1359-1367.

Deary, I.J., Bastin, M.E., Pattie, A., Clayden, J. D., Whalley, L. J., Starr, J. M., and Wardlaw, J. M. (2006). White matter integrity and cognition in childhood and old age. Neurology 66, 505-512.

Deary, I. J., Johnson, W., and Starr, J. M. (2010). Are processing speed tasks biomarkers of cognitive aging? Psychol. Aging 25, 219-228.

DeCarli, C., Massaro, J., Harvey, D., Hald, J., Tullberg, M., Au, R., Beiser, A., D'Agostino, R., and Wolf, P.A. (2005). Measures of brain morphology and infarction in the Framingham heart study: establishing what is normal. Neurobiol. Aging 26, 491-510.

Desmond, J. E., Chen, S. H., and Shieh, P. B. (2005). Cerebellar transcranial magnetic stimulation impairs verbal working memory. Ann. Neurol. 58, 553-560.

Dickstein, D. L., Kabaso. D., Rocher, A. B. Luebke, J. I., Wearne, S. L., and Hof, P. R. (2007). Changes in the structural complexity of the aged brain. Aging Cell 6, 275-284.

Eckert, M. A., Kamdar, N. V., Chang, C. E., Beckmann, C. F., Greicius, M. D., and Menon, V. (2008a). A cross-modal system linking primary auditory and visual cortices: evidence from intrinsic fMRI connectivity analysis. Hum. Brain Mapp. 29, 848-857.

Eckert, M. A., Walczak, A., Ahlstrom, J., Denslow, S., Horwitz, A., and Dubno, J. R. (2008b). Age-related effects on word recognition: reliance on cognitive control systems with structural declines in speech-responsive cortex. J. Assoc. Res. Otolaryngol. 9, 252-259.

Eckert, M. A., Keren, N. I., Roberts, D. R., Calhoun, V. D., and Harris, K. C. (2010). Age-related changes in processing speed: unique contributions of cerebellar and prefrontal cortex. Front. Hum. Neurosci. 4:10. doi: 10.3389/neuro.09.010.2010

Eckert, M. A., Leonard, C. M., Richards, T. L., Aylward, E. H., Thomson, J., and Berninger,V.W.(2003). Anatomical correlates of dyslexia: frontal and cerebellar findings. Brain 126(Pt 2), 482-494.

Feld, J. E., and Sommers, M. S. (2009). Lipreading, processing speed, and working memory in younger and older adults. J. Speech Lang. Hear. Res. 52, 1555-1565.

Finkel, D., Reynolds, C. A., McArdle, J. J., Hamagami, F., and Pedersen, N. L. (2009). Genetic variance in processing speed drives variation in aging of spatial and memory abilities. Dev. Psychol. $45,820-834$.

Fjell, A. M., and Walhovd, K. B. (2010). Structural brain changes in aging: courses, causes and cognitive consequences. Rev. Neurosci. 21, 187-221.
Fjell, A. M., Westlye, L. T., Amlien, I., Espeseth, T., Reinvang, I., Raz, N., Agartz, I., Salat, D. H., Greve, D. N., Fischl, B., Dale, A. M., and Walhovd, K. B. (2009). High consistency of regional cortical thinning in aging across multiple samples. Cereb. Cortex 19, 2001-2012.

Fujikado, T., and Noda, H. (1987). Saccadic eye movements evoked by microstimulation of lobule VII of the cerebellar vermis of macaque monkeys. J. Physiol. 394, 573-594.

Giorgio, A., Santelli, L., Tomassini, V., Bosnell, R., Smith, S., De Stefano, N., and Johansen-Berg, H. (2010). Agerelated changes in grey and white matter structure throughout adulthood. Neuroimage 51, 943-951.

Good, C. D., Johnsrude, I. S., Ashburner, J., Henson, R. N., Friston, K. J., and Frackowiak, R. S. (2001). A voxelbased morphometric study of ageing in 465 normal adult human brains. Neuroimage 14(Pt 1), 21-36.

Grady, C. L., McIntosh, A. R., and Craik, F. I. (2005). Task-related activity in prefrontal cortex and its relation to recognition memory performance in young and old adults. Neuropsychologia 43 , 1466-1481.

Grady, C. L., Springer, M. V., Hongwanishkul, D., McIntosh, A. R. and Winocur, G. (2006). Age-related changes in brain activity across the adult lifespan. J. Cogn. Neurosci. 18, 227-241.

Greany, J. F., and Di Fabio, R. P. (2008) Saccade to stepping delays in elders at high risk for falling. Aging Clin. Exp. Res. 20, 428-433.

Grieve, S. M., Williams, L. M., Paul, R. H., Clark, C. R., and Gordon, E. (2007) Cognitive aging, executive function, and fractional anisotropy: a diffusion tensor MR imaging study. AJNR Am J. Neuroradiol. 28, 226-235.

Gunning-Dixon, F. M., Brickman, A. M., Cheng, J. C., and Alexopoulos, G. S. (2009). Aging of cerebral white matter: a review of MRI findings. Int. J. Geriatr. Psychiatry 24, 109-117.

Gunning-Dixon, F.M., and Raz, N. (2000). The cognitive correlates of white matter abnormalities in normal aging: a quantitative review. Neuropsychology 14, 224-232.

Guo, Z., Jiang, H., Xu, X., Duan, W., and Mattson, M. P. (2008). Leptinmediated cell survival signaling in hippocampal neurons mediated by JAK STAT3 and mitochondrial stabilization. J. Biol. Chem. 283, 1754-1763.

Habas, C., Kamdar, N., Nguyen, D., Prater, K., Beckmann, C. F., Menon, V., and Greicius, M. D. (2009). Distinct cerebellar contributions to intrinsic connectivity networks. J. Neurosci. 29, 8586-8594.
Hall, T. C., Miller, A. K. C., and Corsellis, J. A. N. (1975). Variations in the human Purkinje cell population according to age and sex. Neuropathol. Appl. Neurobiol. 1, 267-292.

Harris, K. C., Dubno, J. R., Keren, N. I., Ahlstrom, J. B., and Eckert, M. A. (2009). Speech recognition in younger and older adults: a dependency on low-level auditory cortex. J. Neurosci. 29, 6078-6087.

Harris, K. C., Eckert, M.A., Ahlstrom, J. B., and Dubno, J. R. (2010). Age-related differences in gap detection: effects of task difficulty and cognitive ability. Hear. Res. 264, 21-29.

Hasher, L., and Zacks, R. T. (1988). Working memory, comprehension, and aging: a review and a new view. Psychol. Learn. Motiv. 22, 193-225.

Hasher, L., Zacks, R. T., and May, C. P. (1999). Inhibitory Control, Circadian Arousal, and Age. Cambridge, MA: MIT Press.

Hayakawa, Y., Nakajima, T., Takagi, M., Fukuhara, N., and Abe, H. (2002). Human cerebellar activation in relation to saccadic eye movements: a functional magnetic resonance imaging study. Ophthalmologica 216, 399-405.

Heneka, M. T., Nadrigny, F., Regen, T., Martinez-Hernandez,A., DumitrescuOzimek, L., Terwel, D., JardanhaziKurutz, D., Walter, J., Kirchhoff, F., Hanisch, U.-K., and Kummer, M. P. (2010). Locus coeruleus controls Alzheimer's disease pathology by modulating microglial functions through norepinephrine. Proc. Natl. Acad. Sci. U.S.A. 107, 6058-6063.

Hogan, M. J. (2004). The cerebellum in thought and action: a fronto-cerebellar aging hypothesis. New Ideas Psychol. 22, 97-125.

Hogan, M. J., Staff, R. T., Bunting, B. P., Murray, A. D., Ahearn, T. S., Deary, I. J., and Whalley, L. J. (2011). Cerebellar brain volume accounts for variance in cognitive performance in older adults. Cortex 47, 441-450.

Hoth, K. F., Tate, D. F., Poppas, A., Forman, D. E., Gunstad, J., Moser, D. J., Paul, R. H., Jefferson, A. L., Haley, A. P., and Cohen, R. A. (2007). Endothelial function and white matter hyperintensities in older adults with cardiovascular disease. Stroke 38, 308-312.

Ivry, R. (1997). Cerebellar timing systems. Int. Rev. Neurobiol. 41, 555-573.

Jacobs, B., and Scheibel, A. B. (1993). A quantitative dendritic analysis of Wernicke's area in humans. I. Lifespan changes. J. Comp. Neurol. 327, 83-96.

Jernigan, T. L., Archibald, S. L., FennemaNotestine, C., Gamst, A. C., Stout, J.C. Bonner, J., and Hesselink, J. R. (2001). Effects of age on tissues and regions of the cerebrum and cerebellum. Neurobiol. Aging 22, 581-594. 
Jokinen, H., Ryberg, C., Kalska, H., Ylikoski, R., Rostrup, E., Stegmann, M. B., Waldemar, G., Madureira, S., Ferro, J. M., van Straaten, E. C., Scheltens, P., Barkhof, F., Fazekas, F., Schmidt, R., Carlucci, G., Pantoni, L., Inzitari, D., and Erkinjuntti, T.; LADIS group. (2007). Corpus callosum atrophy is associated with mental slowing and executive deficits in subjects with agerelated white matter hyperintensities: the LADIS Study. J. Neurol. Neurosurg. Psychiatr. 78, 491-496.

Kelly, A. M., Uddin, L. Q., Biswal, B. B., Castellanos, F. X., and Milham, M. P. (2008). Competition between functional brain networks mediates behavioral variability. Neuroimage 39, 527-537.

Kelly, R. M., and Strick, P. L. (2003). Cerebellar loops with motor cortex and prefrontal cortex of a nonhuman primate. J. Neurosci. 23, 8432-8444.

Kennedy, K. M., and Raz, N. (2005). Age, sex and regional brain volumes predict perceptual-motor skill acquisition. Cortex 41, 560-569.

Kennedy, K. M., and Raz, N. (2009a). Aging white matter and cognition: differential effects of regional variations in diffusion properties on memory, executive functions, and speed. Neuropsychologia 47, 916-927.

Kennedy, K. M., and Raz, N. (2009b). Pattern of normal age-related regional differences in white matter microstructure is modified by vascular risk. Brain Res. 1297, 41-56.

Kennedy, K. M., Rodrigue, K. M., Head, D., Gunning-Dixon, F., and Raz, N. (2009). Neuroanatomical and cognitive mediators of age-related differences in perceptual priming and learning. Neuropsychology 23, 475-491.

Kim, J. M., Stewart, R., Bae, K. Y., Kim, S. W., Yang, S. J., Park, K. H., Shin, I. S., and Yoon, J.S. (in press). Role of BDNF val66met polymorphism on the association between physical activity and incident dementia. Neurobiol. Aging.

Kochunov, P., Coyle, T., Lancaster, J., Robin, D. A., Hardies, J., Kochunov, V., Bartzokis, G., Stanley, J., Royall, D., Schlosser, A. E., Null, M., and Fox, P. T. (2010). Processing speed is correlated with cerebral health markers in the frontal lobes as quantified by neuroimaging. Neuroimage 49 , 1190-1199.

Kramer, A. F., Hahn, S., Irwin, D. E., and Theeuwes, J. (1999). Attentional capture and aging: implications for visual search performance and oculomotor control. Psychol. Aging 14, 135-154.

Krienen, F. M., and Buckner, R. L. (2009). Segregated fronto-cerebellar circuits revealed by intrinsic functional connectivity. Cereb. Cortex 19, 2485-2497.
Kuo, H. K., Chen, C. Y., Liu, H. M., Yen, C. J., Chang, K. J., Chang, C. C., Yu, Y. H., Lin, L. Y., and Hwang, J. J. (2010). Metabolic risks, white matter hyperintensities, and arterial stiffness in high-functioning healthy adults. Int J. Cardiol. 143, 184-191.

Laasonen, M., Lahti-Nuuttila, P., and Virsu, V. (2002). Developmentally impaired processing speed decreases more than normally with age. Neuroreport 13, 1111-1113.

Lee, C. K., Weindruch, R., and Prolla, T. A. (2000). Gene-expression profile of the ageing brain in mice. Nat. Genet. 25, 294-297.

Lee, J.E., Chung, M. K., Lazar, M., DuBray, M. B., Kim, J., Bigler, E. D., Lainhart, J. E., and Alexander,A. L. (2009). A study of diffusion tensor imaging by tissuespecific, smoothing-compensated voxel-based analysis. Neuroimage 44, 870-883.

Lemaitre, H., Crivello, F., Grassiot, B., Alperovitch, A., Tzourio, C., and Mazoyer, B. (2005). Age- and sexrelated effects on the neuroanatomy of healthy elderly. Neuroimage 26, 900-911.

MacLeod, A., and Summerfield, Q. (1987). Quantifying the contribution of vision to speech perception in noise. $\mathrm{Br}$. J. Audiol. 21, 131-141.

MacLullich, A. M., Edmond, C. L., Ferguson, K. J., Wardlaw, J. M., Starr, J.M., Seckl, J. R., and Deary, I. J. (2004). Size of the neocerebellar vermis is associated with cognition in healthy elderly men. Brain Cogn. 56, 344-348. Matochik, J. A., London, E. D., Yildiz, B. O., Ozata, M., Caglayan, S., DePaoli, A. M., Wong, M. L., and Licinio, J. (2005). Effect of leptin replacement on brain structure in genetically leptindeficient adults. J. Clin. Endocrinol. Metab. 90, 2851-2854.

Meunier, D., Achard, S., Morcom, A., and Bullmore, E. (2009). Age-related changes in modular organization of human brain functional networks. Neuroimage 44, 715-723.

Morris, J.C., and McManus, D. Q. (1991). The neurology of aging: normal versus pathologic change. Geriatrics 46, 47-48, 51-44.

Narita, K., Kosaka, H., Okazawa, H., Murata, T., and Wada, Y. (2009). Relationship between plasma leptin level and brain structure in elderly: a voxel-based morphometric study. Biol. Psychiatry 65, 992-994.

Oldreive, C. E., Harvey, J., and Doherty, G. H. (2008). Neurotrophic effects of leptin on cerebellar Purkinje but not granule neurons in vitro. Neurosci. Lett. 438, 17-21.

Ota, M., Nemoto, K., Sato, N., Mizukami, K., Yamashita, F., and Asada, T. (2010). Relationship between white matter $\mathrm{T} 2$ hyperintensity and cortical volume changes on magnetic resonance imaging in healthy elders. Int. J. Geriatr. Psychiatry. doi: 10.1002/gps.2618. [Epub ahead of print].

Paul, R., Grieve, S. M., Chaudary, B., Gordon, N., Lawrence, J., Cooper, N., Clark, C. R., Kukla, M., Mulligan, R. and Gordon, E. (2009). Relative contributions of the cerebellar vermis and prefrontal lobe volumes on cognitive function across the adult lifespan. Neurobiol. Aging 30, 457-465.

Penke, L., Muñoz Maniega, S., Murray, C., Gow, A. J., Hernández, M. C., Clayden, J.D., Starr, J.M., Wardlaw, J. M., Bastin, M.E., and Deary, I. J. (2010). A general factor of brain white matter integrity predicts information processing speed in healthy older people. J. Neurosci. 30, 7569-7574.

Peters, A. (2009). The effects of normal aging on myelinated nerve fibers in monkey central nervous system. Front. Neuroanat. 3:11. doi: 10.3389/ neuro.05.011.2009

Ploner, C. J., Gaymard, B. M., RivaudPechoux, S., and Pierrot-Deseilligny, C. (2005). The prefrontal substrate of reflexive saccade inhibition in humans. Biol. Psychiatry 57, 1159-1165.

Pratt, J., Dodd, M., and Welsh, T. (2006). Growing older does not always mean moving slower: examining aging and the saccadic motor system. J. Mot Behav. 38, 373-382.

Raz, N. (2000). "Aging of the brain and its impact on cognitive performance: integration of structural and functional findings," in The Handbook of Aging and Cognition, eds F. I. M. Craik and T. A. Salthouse (London: Lawrence Erlbaum), 1-90.

Raz, N., Ghisletta, P., Rodrigue, K. M., Kennedy, K. M., and Lindenberger, U. (2010). Trajectories of brain aging in middle-aged and older adults: regional and individual differences. Neuroimage 51, 501-511.

Raz, N., Gunning, F. M., Head, D., Dupuis, J. H., McQuain, J., Briggs, S. D., Loken, W. J., Thornton, A. E., and Acker, J. D. (1997). Selective aging of the human cerebral cortex observed in vivo: differential vulnerability of the prefrontal gray matter. Cereb. Cortex 7, 268-282.

Raz, N., Lindenberger, U., Ghisletta, P., Rodrigue, K. M., Kennedy, K. M., and Acker, J. D. (2008). Neuroanatomical correlates of fluid intelligence in healthy adults and persons with vascular risk factors. Cereb. Cortex 18, 718-726.

Raz, N., Lindenberger, U., Rodrigue, K.M., Kennedy, K. M., Head, D., Williamson, A., Dahle, C., Gerstorf, D., and Acker, J.D. (2005). Regional brain changes in aging healthy adults: general trends, individual differences and modifiers. Cereb. Cortex 15, 1676-1689.
Raz, N., and Rodrigue, K. M. (2006). Differential aging of the brain: patterns, cognitive correlates and modifiers. Neurosci. Biobehav. Rev. 30, 730-748.

Raz, N., Rodrigue, K. M., and Acker, J. D. (2003). Hypertension and the brain: vulnerability of the prefrontal regions and executive functions. Behav. Neurosci. 117, 1169-1180.

Raz, N., Rodrigue, K. M., Kennedy, K. M., and Land, S. (2009). Genetic and vascular modifiers of age-sensitive cognitive skills: effects of COMT, BDNF, ApoE, and hypertension. Neuropsychology 23, 105-116.

Raz, N., Williamson, A., Gunning-Dixon, F., Head, D., and Acker, J. D. (2000). Neuroanatomical and cognitive correlates of adult age differences in acquisition of a perceptual-motor skill. Microsc. Res. Tech. 51, 85-93.

Resnick, S. M., Pham, D. L., Kraut, M. A., Zonderman, A. B., and Davatzikos, C. (2003). Longitudinal magnetic resonance imaging studies of older adults: a shrinking brain. J. Neurosci. 23, 3295-3301.

Rosano, C., Aizenstein, H., Brach, J., Longenberger, A., Studenski, S., and Newman, A. B. (2008). Special article: gait measures indicate underlying focal gray matter atrophy in the brain of older adults. J. Gerontol. A Biol. Sci. Med. Sci. 63, 1380-1388.

Rosano, C., Aizenstein, H. J., Studenski, S., and Newman, A. B. (2007). A regionsof-interest volumetric analysis of mobility limitations in communitydwelling older adults. J. Gerontol. A Biol. Sci. Med. Sci. 62, 1048-1055.

Rosano, C., Venkatraman, V. K., Guralnik, J., Newman, A. B., Glynn, N. W., Launer, L., Taylor, C. A., Williamson, J., Studenski, S., Pahor, M., and Aizenstein, H. (2010). Psychomotor speed and functional brain MRI 2 years after completing a physical activity treatment. J. Gerontol. A Biol. Sci. Med. Sci. 65, 639-647.

Salat, D. H., Buckner, R. L., Snyder, A. Z., Greve, D. N., Desikan, R. S., Busa, E., Morris, J.C., Dale, A. M., and Fischl, B. (2004). Thinning of the cerebral cortex in aging. Cereb. Cortex 14, 721-730.

Salthouse, T. A. (2009). When does age-related cognitive decline begin? Neurobiol. Aging 30, 507-514.

Salthouse, T. A., and Ferrer-Caja, E. (2003). What needs to be explained to account for age-related effects on multiple cognitive variables? Psychol. Aging 18, 91-110.

Salthouse, T. A., Toth, J., Daniels, K., Parks, C., Pak, R., Wolbrette, M., and Hocking, K. J. (2000). Effects of aging on efficiency of task switching in a variant of the trail making test. Neuropsychology 14, 102-111. 
Schiavone, F., Charlton, R. A., Barrick, T. R., Morris, R. G., and Markus, H. S. (2009). Imaging age-related cognitive decline: a comparison of diffusion tensor and magnetization transfer MRI. J. Magn. Reson. Imaging 29, 23-30.

Schmahmann, J. D. (2010). The role of the cerebellum in cognition and emotion: personal reflections since 1982 on the dysmetria of thought hypothesis, and its historical evolution from theory to therapy. Neuropsychol. Rev. 20, 236-260.

Schretlen, D., Pearlson, G. D., Anthony, J. C., Aylward, E. H., Augustine, A. M., Davis, A., and Barta, P. (2000). Elucidating the contributions of processing speed, executive ability, and frontal lobe volume to normal agerelated differences in fluid intelligence. J. Int. Neuropsychol. Soc. 6, 52-61.

Sharpe, J. A., and Zackon, D. H. (1987). Senescent saccades. Effects of aging on their accuracy, latency and velocity. Acta Otolaryngol. 104, 422-428.

Silbert, L. C., Howieson, D. B., Dodge, H., and Kaye, J. A. (2009). Cognitive impairment risk: white matter hyperintensity progression matters. Neurology 73, 120-125.

Soderlund, H., Nyberg, L., Adolfsson, R., Nilsson, L. G., and Launer, L. J. (2003). High prevalence of white matter hyperintensities in normal aging: relation to blood pressure and cognition. Cortex 39, 1093-1105.

Sridharan, D., Levitin, D. J., Chafe, C. H., Berger, J., and Menon, V. (2007). Neural dynamics of event segmentation in music: converging evidence for dissociable ventral and dorsal networks. Neuron 55, 521-532.

Steinlin, M. (2007). The cerebellum in cognitive processes: supporting studies in children. Cerebellum 6, 237-241.

Sweeney, J. A., Rosano, C., Berman, R. A., and Luna, B. (2001). Inhibitory control of attention declines more than working memory during normal aging. Neurobiol. Aging 22, 39-47.

Tisserand, D. J., Pruessner, J. C., Sanz Arigita, E. J., van Boxtel, M. P., Evans,
A. C., Jolles, J., and Uylings, H. B. (2002). Regional frontal cortical volumes decrease differentially in aging: an MRI study to compare volumetric approaches and voxel-based morphometry. Neuroimage 17, 657-669.

Tisserand, D. J., van Boxtel, M. P., Pruessner, J. C., Hofman, P., Evans, A. C., and Jolles, J. (2004). A voxel-based morphometric study to determine individual differences in gray matter density associated with age and cognitive change over time. Cereb. Cortex 14, 966-973.

Townsend, J., Adamo, M., and Haist, F. (2006). Changing channels: an fMRI study of aging and cross-modal attention shifts. Neuroimage 31, 1682-1692.

Turken, A., Whitfield-Gabrieli, S., Bammer, R., Baldo, J. V., Dronkers, N. F., and Gabrieli, J. D. (2008). Cognitive processing speed and the structure of white matter pathways: convergent evidence from normal variation and lesion studies. Neuroimage 42, 1032-1044.

United Nations, Department of Economic and Social Affairs, Population Division (2007). World Population Prospects: The 2006 Revision, Highlights, Working Paper No. ESA/P/WP.202.

Vaughan, D. W. (1977). Age-related deterioration of pyramidal cell basal dendrites in rat auditory cortex. J. Comp. Neurol. 171, 501-515.

Vernooij, M. W., de Groot, M., van der Lugt, A., Ikram, M. A., Krestin, G. P., Hofman, A., Niessen, W. J., and Breteler, M. M. (2008). White matter atrophy and lesion formation explain the loss of structural integrity of white matter in aging. Neuroimage 43, 470-477.

Vernooij, M. W., Ikram, M. A., Vrooman, H. A., Wielopolski, P. A., Krestin, G. P., Hofman, A., Niessen, W. J., Van der Lugt, A., and Breteler, M. M. (2009). White matter microstructural integrity and cognitive function in a general elderly population. Arch. Gen. Psychiatry 66, 545-553.

Vidal, J. S., Sigurdsson, S., Jonsdottir, M. K., Eiriksdottir, G., Thorgeirsson,
G., Kjartansson, O., Garcia, M. E., van Buchem, M. A., Harris, T. B. Gudnason, V., and Launer, L. J. (2010). Coronary artery calcium, brain function and structure: the AGESReykjavik Study. Stroke 41, 891-897.

Voss, M. W., Erickson, K. I., Prakash, R. S., Chaddock, L., Malkowski, E., Alves, H., Kim, J. S., Morris, K. S., White, S. M., Wójcicki, T. R., Hu, L., Szabo, A., Klamm, E., McAuley, E., and Kramer, A. F. (2010). Functional connectivity: a source of variance in the association between cardiorespiratory fitness and cognition? Neuropsychologia 48 , 1394-1406.

Wahl,H.W., Schmitt, M., Danner, D., and Coppin, A. (2010). Is the emergence of functional ability decline in early old age related to change in speed of cognitive processing and also to change in personality? J. Aging Health 22, 691-712.

West, R. L. (1996). An application of prefrontal cortex function theory to cognitive aging. Psychol. Bull. 120, 272-292.

Westlye, L. T., Walhovd, K. B., Dale, A M., Bjørnerud, A., Due-Tønnessen, P., Engvig, A., Grydeland, H., Tamnes, C. K., Ostby, Y., and Fjell, A. M. (2010). Life-span changes of the human brain white matter: diffusion tensor imaging (DTI) and volumetry. Cereb. Cortex 20, 2055-2068.

Willette, A. A., Bendlin, B. B., McLaren, D. G., Canu, E., Kastman, E. K., Kosmatka, K. J., Xu, G., Field, A. S., Alexander, A. L., Colman, R. J., Weindruch, R. H., Coe, C. L., and Johnson, S. C. (2010). Age-related changes in neural volume and microstructure associated with interleukin- 6 are ameliorated by a calorie-restricted diet in old rhesus monkeys. Neuroimage 51, 987-994.

Willis, L. M., Freeman, L., Bickford, P. C., Quintero, E. M., Umphlet, C. D., Moore,A.B., Goetzl,L., and Granholm, A. C. (2010). Blueberry supplementation attenuates microglial activation in hippocampal intraocular grafts to aged hosts. Glia 58, 679-690.
Woodruff-Pak, D. S., Goldenberg, G., Downey-Lamb, M. M., Boyko, O. B., and Lemieux, S. K. (2000). Cerebellar volume in humans related to magnitude of classical conditioning. Neuroreport 11, 609-615.

Woodruff-Pak, D. S., Vogel, R. W., Ewers, M., Coffey, J., Boyko, O. B., and Lemieux, S. K. (2001). MRI-assessed volume of cerebellum correlates with associative learning. Neurobiol. Learn. Mem. 76, 342-357.

Xu, L., Groth, K. M., Pearlson, G., Schretlen, D. J., and Calhoun, V. D. (2009). Source-based morphometry: the use of independent component analysis to identify gray matter differences with application to schizophrenia. Hum. Brain Mapp. 30, 711-724.

Zimmerman, M. E., Brickman, A. M., Paul, R. H., Grieve, S. M., Tate, D. F., Gunstad, J., Cohen, R. A., Aloia, M. S., Williams, L. M., Clark, C. R., Whitford, T. J., and Gordon, E. (2006). The relationship between frontal gray matter volume and cognition varies across the healthy adult lifespan. Am. J. Geriatr. Psychiatry 14, 823-833.

Conflict of Interest Statement: The author declares that the research was conducted in the absence of any commercial or financial relationships that could be construed as a potential conflict of interest.

Received: 22 November 2010; accepted: 15 February 2011; published online: 11 March 2011

Citation: Eckert MA (2011) Slowing down: age-related neurobiological predictors of processing speed Front. Neurosci. 5:25. doi: 10.3389/fnins.2011.00025

Copyright (c) 2011 Eckert. This is an open-access article subject to an exclusive license agreement between the authors and Frontiers Media SA, which permits unrestricted use, distribution, and reproduction in any medium, provided the original authors and source are credited. 